\title{
A Model for Estimating Daily Ozone Dose for Plants from Atmospheric Ozone Concentration and Vapor Pressure Deficit
}

\author{
Gail Rubin, Charles E. McCulloch
}

Biometrics Unit, Cornell University, Ithaca, N.Y. 14853, U.S.A.

and

John A. Laurence

Boyce Thompson Institute for Plant Research, Cornell University, Ithaca, N.Y. 14853, U.S.A. 


\title{
A Model for Estimating Daily Ozone Dose for Plants from Atmospheric Ozone Concentration and Vapor Pressure Deficit
}

\author{
Gail Rubin, Charles E. McCulloch \\ Biometrics Unit, Cornell University, Ithaca, N.Y. 14853, U.S.A. \\ and
}

John A. Laurence

Boyce Thompson Institute for Plant Research, Cornell University, Ithaca, N.Y. 14853, U.S.A.

\begin{abstract}
Ozone is the most important plant-damaging air pollutant in the United States today, causing annual crop losses estimated at greater than two billion dollars. The atmospheric ozone concentration that surrounds a plant is not the concentration that actually impinges upon the plant cells, because the plant's cuticle acts as a barrier to direct diffusion of ozone into cells for much of the plant surface. The primary avenue for ozone entry is via the stomata, which are adjustable pores in the epidermis. Ozone production and vapor pressure deficit (VPD) exhibit nonlinear diurnal cycles, which vary from location to location and, at a given location, vary with the seasons. VPD, a measure of the joint effect of temperature and humidity on the water potential gradient between a plant surface and the air, is highly correlated with stomatal closing and can be calculated from atmospheric data. Each plant species has its own threshold set of VPD and atmospheric ozone concentration, below which stomates are fully open and above which stomates are closed. Hence, combining ozone and VPD data with knowledge of how these variables affect the stomata allows one to model the effective ozone dose reaching the plant cells, a dose which typically cannot be measured directly.

In this paper, we derive a diffusion model, consistent with Fick's first law, that predicts the ozone concentration reaching the cells adjacent to the substomatal cavity at a given time, using the concurrent ambient ozone concentration and VPD together with species-specific thresholds of ozone concentration and VPD below which stomates are fully open and above which stomates are closed.
\end{abstract}


Combining this diffusion model with particular functional forms for the daily curves of atmospheric ozone concentration and VPD allows one to calculate the expected daily ozone dose that the plant's cells receive and the variance of that dose. In addition, this methodology can be modified using hierarchical models to provide realistic regional estimates of the effective daily ozone dose for a species and the variance of the dose, which reflect the regional variation in the diurnal cycles of both atmospheric ozone concentration and VPD. The ozone dose and its variance predicted by this model can be used to assess ozone impact on red spruce in the northeastern US.

Key Words and Phrases: pollution, hierarchical models, regional estimates, nonlinear mixed models. 


\section{Introduction}

Ozone is the most important plant-damaging air pollutant in the United States today. Crop loss due to ozone may exceed two billion dollars annually in the U.S. alone, with significant impacts on agricultural productivity also occurring in the rest of North America and Europe (US Environmental Protection Agency 1986, 1994). The economic and ecological impact of ozone on forest growth and productivity is as yet unknown but may be great due to the long life of trees, which results in exposure to the pollutant over years or decades (US Environmental Protection Agency 1994).

Estimating the concentration of ozone to which the cells of a plant are actually exposed has been problematic. Under carefully controlled conditions, using specialized equipment, it is possible to measure directly the flux of ozone to the plant cells. However, under most experimental conditions, including season-long exposures, and for regional assessments of the impact of ozone, such a measurement is impossible. Thus, the concentration of ozone in the air near the plants has been used as a surrogate for the actual exposure dose. In some cases, the atmospheric concentration of ozone is a good estimate; however, under conditions such as drought, high evaporative demand or darkness, the internal concentration of ozone may differ substantially from that in the air.

To protect vegetation from ozone, the U.S. Environmental Protection Agency has established standards (secondary National Ambient Air Quality Standards), which are based upon demonstrated effects of known concentrations of ozone on the growth, yield, productivity or appearance of agricultural crops, ornamentals, forest trees and other vegetation (US Environmental Protection Agency 1986; Tingey et al. 1990, 1991). Generally, exposure-response relationships are established through experimentation and used as an indicator, or in some cases as a predictor, of adverse effects. These relationships work well when the ambient concentration of ozone is a reasonable surrogate for the actual exposure dose, but may fail under conditions where a process such as stomatal closure due to drought alters the uptake of ozone by the plant. This becomes particularly important for inferences on a regional basis, where exposure-response relationships developed under optimal growing conditions may not correctly predict the response of plants exposed to the rigors of the environment. The objective of this research was to provide a better method for estimating the effective ozone concentration. 
Previous studies (Runeckles and Chevone 1992) have demonstrated the differential response of plants to ozone in relation to the status of several environmental factors. In particular, the water status of the plant, determined by internal water potential, soil water potential or vapor pressure deficit (VPD), often will control the stomatal aperture, resulting in greater or lesser exchanges of gases $\left(\mathrm{CO}_{2}, \mathrm{H}_{2} \mathrm{O}\right.$, as well as atmospheric pollutants). Further, high concentrations of ozone tend to accumulate under conditions of atmospheric stagnation, when temperatures may be high, and transpiration by the plants high or low, depending on species and water status. Such factors not only make prediction of the response of a plant to ozone difficult, but they obscure the establishment of air quality standards.

A variety of methods have been tried to adjust ozone dose to improve correlations with plant response. For the most part, these are regression models relating the plant response to ozone dose averaged over time (Cure et al. 1986; Larson and Heck 1976; Krupa and Nosal 1989), or utilization of ozone dose thresholds (Oshima et al. 1976), or arbitrary assignments of weighting factors (Lefohn and Runeckles 1987; Lefohn et al. 1988; Lefohn and Foley 1992). In most cases the various metrics of ozone dose are highly correlated; one works as well as, but no better than, others. In an attempt to adjust an ozone dose to account for the occurrence of visible injury, MacDowall et al. (1964) modified measured ozone concentration by an evaporation index. They used this method of calculating short-term exposure to explain variation in the occurrence of weather fleck, visible leaf necrosis due to ozone. However, to date, adjustment methods for seasonal ozone doses have not been developed which can account for either visible injury or other measures of the impact of ozone, such as yield or changes in chemical components of plants.

In this paper, we derive a model that predicts the ozone concentration reaching the cells adjacent to the substomatal cavity as a function of ambient ozone concentration and VPD. We have applied the model to data sets collected from the exposure of red spruce (Picea rubens) and wheat (Triticum aestivum) to ozone under field conditions in several years and, for red spruce, at several different sites in the northeastern U.S. (Fincher et al. 1989; Amundson et al. 1992; Kohut et al. 1987). The data sets were selected to investigate the behavior of the model with a species that has a stomatal response to 
VPD (red spruce) as well as with one that lacks this response (wheat). In addition, we extend the methodology to provide realistic regional estimates of effective ozone dose for a given species. Both the location-specific and regional estimates of daily ozone dose based on this diffusion model are easy to calculate. For example, if the diurnal curves of atmospheric ozone concentration and VPD are bellshaped, then the local and regional estimates of daily ozone dose are linear combinations of normal and t probabilities, respectively.

\section{Model Development and Results}

\subsection{Background}

Our goal in modeling was to obtain an estimate of the daily ozone dose with which a plant must cope which is more realistic than simply using the daily atmospheric ozone concentration as the dose. In physiological studies repeated over seasons conducted with red spruce in Ithaca, NY, we observed that using the atmospheric concentration produced a consistent but peculiar dose-response relationship for several variables (Fincher et al. 1989): the detrimental effects increased with ozone dose for doses of 0.4 to 2 times the ambient ozone concentration (AOC) and then with a dose of three times AOC, the effect declined to a level well below that for AOC. Figure 1 illustrates this phenomenon using the natural logarithm of the number of brown needle clusters (a measure of damage) as a function of applied ozone level. This pattern suggested that the actual ozone dose received by plants to which three times AOC was applied might be considerably less than the applied dose. Our hope was to derive an estimate of the ozone dose received by the plants which would be better than previously derived adjustments and would permit making the dose-response relationships more intelligible.

A statistical model, which incorporates experimentally verified biological theory, was developed to adjust the applied ozone dose to that in the substomatal cavity (the site in the leaf where diffusion of gases into the ceils occurs) and, thus, experienced by the plânt cells in direct contact with the cavity. Ozone production and vapor pressure deficit are processes driven by the sun and exhibit nonlinear diurnal cycles, which vary from location to location and, at a given location, vary with the seasons. For both processes, the diurnal curve is unimodal and curves for individual days can be symmetric or 
skewed. Curves based on the average of several days from the same season are unimodal and relatively symmetric. VPD measures the joint effect of temperature and humidity on the water potential gradient between a plant surface and the air and is highly correlated with stomatal closing. Continued high VPD is indicative of drought conditions. VPD has the advantage of being calculable from atmospheric data, whereas direct measurement of stomatal response is both destructive and labor intensive. Ozone must diffuse with water vapor through the stomata in the plant's leaves in order to enter the plant's cells. Each plant species has its own set of thresholds for VPD and atmospheric ozone concentration, below which stomates are fully open and above which stomates are closed. Fick's first law predicts that gas flux across the stomata (and, hence, ozone concentration) should decline linearly with increasing VPD for VPD levels between the threshold values. For VPD or ozone levels above the threshold at which stomates close, the gas flux into the plant depends on the conductance across the cuticle, a waxy layer on the plant surface. Empirical work has verified that gas exchange in the leaf, particularly across stomates, behaves in accordance with Fick's first law (Nobel 1991). Consequently, plant physiologists and ecologists routinely use this physical principle in describing phenomena associated with water relations, photo-synthesis and respiration (Nobel 1991). Incorporating the knowledge of how ozone concentration and VPD affect the stomata, the primary avenue of ozone entry into the plant tissue, into a statistical model allows one to estimate the effective ozone dose reaching the plant cells using atmospheric measurements as the primary data.

\subsection{Regression models for diurnal curves of weather variables}

The fluctuations throughout the day in atmospheric ozone concentration and VPD can be described mathematically as nonlinear regression functions. The atmospheric ozone concentration $\left(\mathrm{Y}_{A}\right)$ at time $\mathrm{t}$ is given by

$$
\mathrm{Y}_{A}(\mathrm{t})=\mathrm{Y}_{A} \mid \mathrm{t}=\alpha+\beta \mathrm{f}_{1}(\mathrm{t})+\epsilon
$$

where $\alpha$ is the baseline ozone concentration at a given location, $\beta$ is a scaling factor, $\mathrm{t}$ is time in hours, ranging from 0 to 24 , and $\epsilon$ is a random error term (e.g., measurement error). We have found it convenient to use $f_{1}(t)$ as a probability density because densities fit well and are computationally convenient and allow specification of the hierarchical model of Section 2.4. Similarly, the vapor 
pressure deficit (D) at time $t$ is given by

$$
\mathrm{D}(\mathrm{t})=\mathrm{D} \mid \mathrm{t}=\kappa+\gamma \mathrm{f}_{2}(\mathrm{t})+\zeta
$$

where $f_{2}(t)$ is a density, $\kappa$ is the baseline VPD at a given location, $\gamma$ is a scaling factor, $t$ is time in hours and $\zeta$ is a random error term. We will let $\theta$ denote the vector of parameters for the regression functions of the diurnal curves of atmospheric ozone concentration and VPD, i.e., $\alpha, \beta, \kappa, \gamma$ plus the parameters of $f_{1}(t)$ and $f_{2}(t)$. These two functions describe processes that are driven by the sun, processes which can be correlated or not.

Correlation analyses of concurrent hourly data for ambient ozone concentration and VPD taken from several locations in the northeastern US over several growing seasons were performed. Calculating the simple correlation (ignoring time trends) between VPD and atmospheric ozone concentration using the hourly data, we found a large positive correlation $(r>0.90)$ in all cases, since both weather variables increase during the early part of the day and then decrease. However, calculating the partial correlation between VPD and atmospheric ozone after accounting for the time trends for each variable, we found little or no correlation between the measured diurnal functions ( $r<0.35$ in all cases). These results indicated that, although the diurnal curves for both VPD and atmospheric ozone concentration are related, the errors about those curves were not tightly coupled in the locations we investigated. However, the processes may be strongly correlated in other locations. Therefore, we develop results for the general model:

$$
\epsilon \sim \mathrm{N}\left(0, \eta^{2}\right), \zeta \sim \mathrm{N}\left(0, \omega^{2}\right), \operatorname{Cov}(\epsilon, \zeta)=\rho \omega \eta
$$

To conveniently express time in a biologically sensible way, we will define time 0 as sunrise. With the notation above, we can write down a model for the ozone concentration entering the plant, which we refer to as the internal ozone concentration. But first, we will describe some candidate models for the regression functions for $\mathrm{Y}_{A}(\mathrm{t})$ and $\mathrm{D}(\mathrm{t})$. Figure 2 illustrates the diurnal curve of ambient ozone and of VPD for an individual day in June of the 1987 growing season in Ithaca, NY.

A convenient candidate for $f_{1}(t)$ or $f_{2}(t)$ when the diurnal curve is symmetric is the normal probability density function (pdf). The inclusion of the scaling factor $(\beta$ or $\gamma$ ) in the regression model provides sufficient flexibility for the normal curve to closely fit the data since the area under the fitted 
curve is constrained by it being a pdf. When the diurnal curve for either $Y_{A}(t)$ or $D(t)$ is skewed, a gamma pdf or a lognormal pdf is a candidate model. Although they are less complicated than densities, we have found that polynomials and sin/cos curves do not provide good fits to diurnal weather data of this type. The normal pdf has the attractive feature of being parameterized in terms of a mean and a variance, which represent the time at which the peak level occurs and the variation about the time at which the peak level occurs. The gamma and lognormal pdfs can be reparameterized in terms of their mean and variance; however, the reparameterized versions are more problematic if one tries to embed them in a hierarchical model to obtain regional estimates of effective daily ozone dose (see Section 2.4). The estimates of daily mean and variance of ozone and VPD obtained from the normal, lognormal and reparameterized gamma model were very similar for each of our data sets. An advantage of using the normal or the gamma pdf as the regression function is that if one wants to integrate the function over time, as in calculating the function's mean or variance, the expressions are closed form and are readily calculable using the normal cumulative distribution function (cdf) or the incomplete gamma function. Conveniently, the normal cdf and the incomplete gamma function (or the chi-square cdf) are available as programmed functions in many statistical software packages (e.g., MINITAB, SAS, JMP, and even Excel), eliminating the need for numerical integration software. A beta model also was investigated, since the beta distribution is known to be very flexible and, depending on its parameter values, it can be symmetric or skewed. Like the normal and gamma models, means and variances of the regression function are easily calculable using the beta, here via the incomplete beta function. Unfortunately, the scaled beta model did not provide as good a fit as the scaled normal and the scaled gamma or lognormal models to symmetric and skewed data, respectively, for either ambient ozone concentration or for VPD. Essentially, it was not able to reproduce the sharpness of the peak values.

When modeling seasonal average curves from these sites, the normal model typically provided a good fit to both daily ozone production and daily vapor pressure deficit. Figure 3A illustrates the fits to the seasonal diurnal curves for ambient ozone at three locations in the northeastern US in 1988. The locations, Ithaca, NY, Howland, ME and Whiteface Mountain, NY, represent, respectively, low 
elevation sites at two different latitudes and one high elevation site. The data for individual days from late May through early July were averaged at each site to provide the hourly data for the seasonal curves at each site. The scaled normal model provided a good fit to each of the three curves, although the curves ranged greatly in sharpness of the ozone peak. The ozone curve for Whiteface Mountain appears relatively flat when plotted with the more obviously unimodal curves for Ithaca and Howland; however, the curve from Whiteface does have a peak, which is more evident when the data are plotted on a different scale. Figure 3B provides the corresponding seasonal diurnal curves for VPD at the three sites. The scaled normal model provided a good fit to the VPD curve for each site. The VPD curve for Whiteface Mountain also was flatter than the corresponding curves for Ithaca and Howland, but all three curves were clearly unimodal. The expected tailing off of VPD at the baseline level during the night is obvious in Figure 3B. In addition, the ozone and VPD curves for Whiteface Mountain illustrate that the diurnal curves for these two processes need not be tightly coupled: ozone concentration was relatively high throughout the 24 -hour period with only a very small peak at hour 15 (9 p.m.), whereas VPD was relatively low throughout the period with a clearly bell-shaped curve, which had a marked peak at 9.5 hours (3:30 p.m.).

\subsection{Basic model for ozone concentration in the plant}

Based on the concurrent ambient ozone concentration and VPD, the model below predicts the ozone concentration $\left(\mathrm{Y}_{I}\right)$ reaching the cells of the substomatal cavity at a given time, as follows:

$$
\mathrm{Y}_{I}(\mathrm{t})= \begin{cases}\mathrm{Y}_{A}(\mathrm{t}) & \text { for } \mathrm{R}_{1}=\left\{\mathrm{t}: \mathrm{Y}_{A}(\mathrm{t})<\mathrm{m}, 0 \leq \mathrm{D}(\mathrm{t})<\nu_{1}\right\} \\ \mathrm{Y}_{A}(\mathrm{t})\left[1-\left(\mathrm{D}(\mathrm{t})-\nu_{1}\right) / \lambda\left(\nu_{2}-\nu_{1}\right)\right] & \text { for } \mathrm{R}_{2}=\left\{\mathrm{t}: \mathrm{Y}_{A}(\mathrm{t})<\mathrm{m}, \nu_{1} \leq \mathrm{D}(\mathrm{t}) \leq \nu_{2}\right\} \\ \mathrm{Y}_{A}(\mathrm{t})\left[\mathrm{k}_{c} /\left(\mathrm{k}_{c}+\mathrm{k}_{s}\right)\right] & \text { for } \mathrm{R}_{3}=\left\{\mathrm{t}: \mathrm{Y}_{A}(\mathrm{t})<\mathrm{m}, \mathrm{D}(\mathrm{t})>\nu_{2}\right\} \\ \mathrm{Y}_{A}(\mathrm{t})\left[\mathrm{k}_{c} /\left(\mathrm{k}_{c}+\mathrm{k}_{s}\right)\right] & \text { for } \mathrm{R}_{4}=\left\{\mathrm{t}: \mathrm{Y}_{A}(\mathrm{t}) \geq \mathrm{m}\right\}\end{cases}
$$

where $\nu_{1}$ and $\nu_{2}$ are the thresholds for VPD, respectively, below which the stomates are fully open and above which stomates are closed; $\lambda$ is the scaling parameter for VPD which allows $\mathrm{Y}_{I}$ to decrease slowly unitil stomatal closure; $\mathrm{m}$ is the threshold for atmospheric ozone concentration above which 
stomates close; and $\mathrm{k}_{c}$ and $\mathrm{k}_{\boldsymbol{s}}$ are the cuticular and stomatal conductances, respectively, all of which except for $\lambda$ are specific to a given plant species. When atmospheric ozone concentration is low to moderate and the level of vapor pressure deficit is low enough that the stomata are open, the ozone concentration entering the substomatal cavity is the atmospheric concentration; this is described by (3a). In most locations for most species, the internal ozone concentration should equal the atmospheric for a large part of the 24-hour period. For low to moderate ozone concentrations and VPD levels between the threshold values, Fick's first law applies so the ozone concentration in the substomatal cavity declines linearly with increasing VPD; this is given by (3b). The importance of the decrease in internal ozone concentration from ambient due to stomatal response to VPD will vary from species to species. For instance, the potential for decline in internal ozone concentration from ambient is relevant for red spruce but plays little role for wheat, which has relatively high thresholds for stomatal response to VPD and ozone. For VPD or ozone levels above the threshold at which stomates close, the gas flux into the plant depends on the conductance across the cuticle; this is described by (3c) and (3d). The contribution to internal ozone concentration made by diffusion across the cuticle will be very small for most plant species and is assumed negligible when the stomates are open.

This model has the advantage of adjusting the ozone dose only when necessary in that small or no adjustments are made to the internal ozone dose for species with weak stomatal responses to VPD or ambient ozone concentration. For instance, when we applied the model to two years of data for wheat, a species that has little stomatal response to VPD, the internal ozone doses calculated were virtually identical to the atmospheric ozone concentrations applied to give the treatment levels. The model also is self-adjusting for seasonal differences in VPD response for a given species. When the weather is cool or there is relatively high humidity, there will be little or no stomatal closing due to VPD and, hence, the model does not alter the internal ozone dose from ambient. This aspect will be illustrated later with data for red spruce.

Under this model, one can derive the expected dose of ozone that a plant receives, $\mathrm{E}\left(\mathrm{Y}_{I} ; \theta\right)$, and the variance of that dose, $\operatorname{Var}\left(\mathrm{Y}_{I} ; \theta\right) . \operatorname{Var}\left(\mathrm{Y}_{I} ; \theta\right)$ is useful for characterizing the inherent variation in the process and for incorporation in the hierarchical model (Section 2.4). The mean and variance are 
dependent on $\theta$, the set of parameters for the regression functions of $\mathrm{Y}_{A}$ and $\mathrm{D}$; but to simplify notation in this section, we will suppress the dependence on $\theta$ in the expressions that follow. The approach used to derive the expected internal ozone concentration (i.e., the effective dose) and its variance was to calculate the mean and variance of internal ozone concentration, conditional on time $t$, and then calculate their unconditional counterparts by iterating the expectations. The latter required using the facts that, for a random variable $\mathrm{X}$,

$$
E(X)=E_{t}[E(X \mid t)]
$$

and

$$
\operatorname{Var}(\mathrm{X})=\operatorname{Var}_{t}[\mathrm{E}(\mathrm{X} \mid \mathrm{t})]+\mathrm{E}_{t}[\operatorname{Var}(\mathrm{X} \mid \mathrm{t})]
$$

and then integrating the components of the conditional moments over the appropriate time intervals, with time in hours being uniformly distributed on the interval $(0,24)$. To obtain the expected daily internal dose and the daily variance of that dose, one merely multiplies $\mathrm{E}\left(\mathrm{Y}_{I} ; \theta\right)$ by 24 and $\operatorname{Var}\left(\mathrm{Y}_{I} ; \theta\right)$ by $24^{2}$.

Using the model in equation (3), the mean internal ozone concentration, conditional on time $t$, is given by

$$
\begin{gathered}
\mathrm{E}\left(\mathrm{Y}_{I} \mid \mathrm{t}\right)=\mathrm{I}_{R_{1}}(\mathrm{t}) \mathrm{E}\left(\mathrm{Y}_{A} \mid \mathrm{t}\right)+\left\{\mathrm{I}_{R_{3}}(\mathrm{t})+\mathrm{I}_{R_{4}}(\mathrm{t})\right\}\left[\mathrm{k}_{c} /\left(\mathrm{k}_{s}+\mathrm{k}_{c}\right)\right] \mathrm{E}\left(\mathrm{Y}_{A} \mid \mathrm{t}\right) \\
+\mathrm{I}_{R_{2}}(\mathrm{t}) \mathrm{E}\left\{\left(\mathrm{Y}_{A} \mid \mathrm{t}\right)\left[1-\left((\mathrm{D} \mid \mathrm{t})-\nu_{1}\right) / \lambda\left(\mathrm{v}_{2}-\nu_{1}\right)\right]\right\}
\end{gathered}
$$

where $\mathrm{I}_{R_{i}}(\mathrm{t})$ is an indictor function for region $\mathrm{R}_{i}$. Similarly, the variance of internal ozone concentration, conditional on time $t$, is given by

$$
\begin{gathered}
\operatorname{Var}\left(\mathrm{Y}_{I} \mid \mathrm{t}\right)=\mathrm{I}_{R_{1}}(\mathrm{t}) \operatorname{Var}\left(\mathrm{Y}_{A} \mid \mathrm{t}\right)+\left\{\mathrm{I}_{R_{3}}(\mathrm{t})+\mathrm{I}_{R_{4}}(\mathrm{t})\right\}\left[\mathrm{k}_{c} /\left(\mathrm{k}_{s}+\mathrm{k}_{c}\right)\right]^{2} \operatorname{Var}\left(\mathrm{Y}_{A} \mid \mathrm{t}\right) \\
+\mathrm{I}_{R_{2}}(\mathrm{t}) \operatorname{Var}\left\{\left(\mathrm{Y}_{A} \mid \mathrm{t}\right)\left[1-\left((\mathrm{D} \mid \mathrm{t})-\nu_{1}\right) / \lambda\left(\mathrm{v}_{2}-\nu_{1}\right)\right]\right\} .
\end{gathered}
$$

Recall from Section 2.2 that the means and variances of ambient ozone and VPD, conditional on time $\mathrm{t}$, are $\mathrm{E}\left(\mathrm{Y}_{\Delta} \mid \mathrm{t}\right)=\alpha+\beta \mathrm{f}_{1}(\mathrm{t}), \mathrm{E}(\mathrm{D} \mid \mathrm{t})=\kappa+\gamma \mathrm{f}_{2}(\mathrm{t}), \operatorname{Var}\left(\mathrm{Y}_{\underline{A}} \mid \mathrm{t}\right)=\eta^{2}$ and $\operatorname{Var}(\mathrm{D} \mid \mathrm{t})=\omega^{2}$. We also need the covariance of $\mathrm{Y}_{A}(\mathrm{t})$ and $\left[1-\left(\mathrm{D}(\mathrm{t})-\nu_{1}\right) / \lambda\left(\mu_{2}-\mu_{1}\right)\right]$, which is

$$
\operatorname{Cov}\left(\left(Y_{A} \mid t\right),\left[1+\left(\nu_{1} / c\right)-(1 / c)(D \mid t)\right]\right)=-\rho \omega \eta(1 / c)
$$

where $c=\lambda\left(\nu_{2}-\nu_{1}\right)$. Accordingly, $E\left(Y_{I} \mid t\right)$ given in (4) equals 


$$
\begin{aligned}
& \mathrm{I}_{R_{1}}(\mathrm{t})\left[\alpha+\beta \mathrm{f}_{1}(\mathrm{t})\right]+\left\{\mathrm{I}_{R_{3}}(\mathrm{t})+\mathrm{I}_{R_{4}}(\mathrm{t})\right\}\left[\alpha+\beta \mathrm{f}_{1}(\mathrm{t})\right]\left[\mathrm{k}_{c} /\left(\mathrm{k}_{s}+\mathrm{k}_{c}\right)\right] \\
& \quad+\mathrm{I}_{R_{2}}(\mathrm{t})\left\{\left[\alpha+\beta \mathrm{f}_{1}(\mathrm{t})\right]\left[1+\nu_{1} / \mathrm{c}\right]-(1 / \mathrm{c})\left[\alpha+\beta \mathrm{f}_{1}(\mathrm{t})\right]\left[\kappa+\gamma \mathrm{f}_{2}(\mathrm{t})\right]-(1 / \mathrm{c}) \rho \omega \eta\right\} .
\end{aligned}
$$

Similar calculations and substitutions into (5) yields

$$
\begin{aligned}
& \operatorname{Var}\left(\mathrm{Y}_{I} \mid \mathrm{t}\right)=\mathrm{I}_{R_{1}}(\mathrm{t}) \eta^{2}+\left\{\mathrm{I}_{R_{3}}(\mathrm{t})+\mathrm{I}_{R_{4}}(\mathrm{t})\right\}\left[\mathrm{k}_{c} /\left(\mathrm{k}_{s}+\mathrm{k}_{c}\right)\right]^{2} \eta^{2} \\
&+ \mathrm{I}_{R_{2}}(\mathrm{t})\left\{\left[1+\left(\nu_{1} / \mathrm{c}\right)-(1 / \mathrm{c})\left[\kappa+\gamma \mathrm{f}_{2}(\mathrm{t})\right]\right]^{2} \eta^{2}+\left[\alpha+\beta \mathrm{f}_{1}(\mathrm{t})\right]^{2}(1 / \mathrm{c})^{2} \omega^{2}\right. \\
&+(1 / \mathrm{c})^{2}\left(1+2 \rho^{2}\right) \omega^{2} \eta^{2}-(1 / \mathrm{c}) \rho \omega \eta \\
&\left.\quad \times\left(2\left[\alpha+\beta \mathrm{f}_{1}(\mathrm{t})\right]\left[1+\left(\nu_{1} / \mathrm{c}\right)-(1 / \mathrm{c})\left[\kappa+\gamma \mathrm{f}_{2}(\mathrm{t})\right]\right]^{2}+(1 / \mathrm{c}) \rho \omega \eta\right)\right\}
\end{aligned}
$$

Now we iterate the expectation to derive the unconditional mean of internal ozone concentration, $\mathrm{E}\left(\mathrm{Y}_{I} ; \theta\right)$, which is given by

$$
\begin{aligned}
& \mathrm{E}\left(\mathrm{Y}_{I} ; \theta\right)=\int_{R_{1}}\left[\alpha+\beta \mathrm{f}_{1}(\mathrm{t})\right](1 / 24) \mathrm{dt}+\left[\mathrm{k}_{c} /\left(\mathrm{k}_{s}+\mathrm{k}_{c}\right)\right] \int_{R_{3} \cup R_{4}}\left[\alpha+\beta \mathrm{f}_{1}(\mathrm{t})\right](1 / 24) \mathrm{dt} \\
& \quad+\left[1+\left(\nu_{1} / \mathrm{c}\right)\right] \int_{R_{2}}\left[\alpha+\beta \mathrm{f}_{1}(\mathrm{t})\right](1 / 24) \mathrm{dt}-(1 / \mathrm{c}) \int_{R_{2}}\left[\alpha+\beta \mathrm{f}_{1}(\mathrm{t})\right]\left[\kappa+\gamma \mathrm{f}_{2}(\mathrm{t})\right](1 / 24) \mathrm{dt} \\
& \quad-(1 / \mathrm{c}) \rho \omega \eta \int_{R_{2}}(1 / 24) \mathrm{dt} .
\end{aligned}
$$

Proceeding similarly, the unconditional variance of the internal ozone concentration is

$$
\operatorname{Var}\left(\mathrm{Y}_{I} ; \theta\right)=\operatorname{Var}_{t}\left[\mathrm{E}\left(\mathrm{Y}_{I} \mid \mathrm{t} ; \theta\right)\right]+\mathrm{E}_{t}\left[\operatorname{Var}\left(\mathrm{Y}_{I} \mid \mathrm{t} ; \theta\right)\right]
$$

We will derive each term on the right-hand side of (10) separately.

$$
\begin{aligned}
\operatorname{Var}_{t}\left[\mathrm{E}\left(\mathrm{Y}_{I} \mid \mathrm{t} ; \theta\right)\right]= & \int_{R_{1}}\left[\alpha+\beta \mathrm{f}_{1}(\mathrm{t})\right]^{2}(1 / 24) \mathrm{dt}-\left(\int_{R_{1}}\left[\alpha+\beta \mathrm{f}_{1}(\mathrm{t})\right](1 / 24) \mathrm{dt}\right)^{2} \\
& +\left[\mathrm{k}_{c} /\left(\mathrm{k}_{s}+\mathrm{k}_{c}\right)\right]^{2}\left\{\int_{R_{3} \cup R_{4}}\left[\alpha+\beta \mathrm{f}_{1}(\mathrm{t})\right]^{2}(1 / 24) \mathrm{dt}-\left(\int_{R_{3} \cup R_{4}}\left[\alpha+\beta \mathrm{f}_{1}(\mathrm{t})\right](1 / 24) \mathrm{dt}\right)^{2}\right\} \\
& +\int_{R_{2}}\left[\alpha+\beta \mathrm{f}_{1}(\mathrm{t})\right]^{2}\left\{1+\left(\nu_{1} / \mathrm{c}\right)-(1 / \mathrm{c})\left[\kappa+\gamma \mathrm{f}_{2}(\mathrm{t})\right]\right\}^{2}(1 / 24) \mathrm{dt} \\
& -\left(\int_{R_{2}}\left[\alpha+\beta \hat{\mathrm{f}}_{1}(\mathrm{t})\right]\left\{\hat{1}+\left(\nu_{1} / \mathrm{c}\right)-(1 / \mathrm{c})\left[\kappa+\gamma \hat{\mathrm{r}}_{2}(\mathrm{t})\right]\right\}(1 / 24) \mathrm{d} \mathrm{t}\right)^{2} .
\end{aligned}
$$




$$
\begin{aligned}
\mathrm{E}_{t}\left[\operatorname{Var}\left(\mathrm{Y}_{I} \mid \mathrm{t} ; \theta\right)\right]=\eta^{2} \int_{R_{1}}(1 / 24) \mathrm{dt}+\left[\mathrm{k}_{c} /\left(\mathrm{k}_{s}+\mathrm{k}_{c}\right)\right]^{2} \int_{R_{3} \cup R_{4}}(1 / 24) \mathrm{dt} \eta^{2} \\
+[(1 / \mathrm{c}) \omega \eta]^{2}\left(1+\rho^{2}\right) \int_{R_{2}}(1 / 24) \mathrm{dt}+\eta^{2}\left[1+\left(\nu_{1} / \mathrm{c}\right)\right]^{2} \int_{R_{2}}(1 / 24) \mathrm{dt} \\
+[(1 / \mathrm{c}) \rho \omega \eta]^{2}\left\{\int_{R_{2}}(1 / 24) \mathrm{dt}-\left(\int_{R_{2}}(1 / 24) \mathrm{dt}\right)^{2}\right\} \\
-2(1 / \mathrm{c}) \eta^{2}\left[1+\left(\nu_{1} / \mathrm{c}\right)\right] \int_{R_{2}}\left[\kappa+\gamma \mathrm{f}_{2}(\mathrm{t})\right](1 / 24) \mathrm{dt} \\
+\eta^{2}(1 / \mathrm{c})^{2} \int_{R_{2}}\left[\kappa+\gamma \mathrm{f}_{2}(\mathrm{t})\right]^{2}(1 / 24) \mathrm{dt}+\omega^{2}(1 / \mathrm{c})^{2} \int_{R_{2}}\left[\alpha+\beta \mathrm{f}_{1}(\mathrm{t})\right]^{2}(1 / 24) \mathrm{dt} \\
+2(1 / \mathrm{c}) \rho \omega \eta\left\{\left[1+\left(\nu_{1} / \mathrm{c}\right)\right] \int_{R_{2}}\left[\alpha+\beta \mathrm{f}_{1}(\mathrm{t})\right](1 / 24) \mathrm{dt}\right. \\
\left.-(1 / \mathrm{c}) \int_{R_{2}}\left[\alpha+\beta \mathrm{f}_{1}(\mathrm{t})\right]\left[\kappa+\gamma \mathrm{f}_{2}(\mathrm{t})\right]^{2}(1 / 24) \mathrm{dt}\right\}
\end{aligned}
$$

Making the appropriate substitutions into (9), (11) and (12) provide closed form expressions for $\mathrm{E}\left(\mathrm{Y}_{I} ; \theta\right)$ and $\operatorname{Var}\left(\mathrm{Y}_{I} ; \theta\right)$ when the regression functions for ambient ozone concentration and VPD are either the scaled normal or the scaled gamma pdf. When $f_{1}(t)$ and $f_{2}(t)$ are normal pdf's, both the mean and variance of internal ozone concentration are linear combinations of normal probabilities. When $\mathrm{f}_{1}(\mathrm{t})$ and $\mathrm{f}_{2}(\mathrm{t})$ are gamma pdf's, then $\mathrm{E}\left(\mathrm{Y}_{I} ; \theta\right)$ and $\operatorname{Var}\left(\mathrm{Y}_{I} ; \theta\right)$ are linear combinations of gamma probabilities, which can be rewritten in terms of chi-square probabilities, if that were more convenient. In either case the mean and variance of internal ozone concentration are straightforward to compute. An estimator of the effective daily ozone dose, $24 \mathrm{E}\left(\mathrm{Y}_{I} ; \theta\right)$, is obtained by substituting into (9) the estimates $\hat{\theta}$ from fitting the regressions for the diurnal curves of atmospheric ozone and VPD along with the species-specific constants. Likewise, an estimator for the variance of daily ozone dose, $24^{2} \operatorname{Var}\left(\mathrm{Y}_{I} ; \widehat{\theta}\right)$, is obtained by making similar substitutions into expressions (11) and (12) for the $\operatorname{Var}\left(\mathrm{Y}_{I} ; \theta\right)$. The expressions for the unconditional means and variances, and for their counterparts that are conditionai on time, simpiify substantiaily if the processes for $\mathbf{Y}_{A}$ and $\mathrm{D}$ are uncorrelaied [i.e., $\operatorname{Cov}(\epsilon, \zeta)=\rho \omega \eta=0]$ and simplify even further if the weather processes are assumed to be independent. The Appendix gives the expressions for $\mathrm{E}\left(\mathrm{Y}_{I} ; \theta\right)$ and $\operatorname{Var}\left(\mathrm{Y}_{I} ; \theta\right)$ when $\mathrm{f}_{1}(\mathrm{t})$ and $\mathrm{f}_{2}(\mathrm{t})$ are normal pdf's with mean and variance parameters $\left(\mu, \sigma^{2}\right)$ and $\left(\phi, \tau^{2}\right)$, respectively, and $\operatorname{Cov}(\epsilon, \zeta)=\rho \omega \eta$. 
We found the model using uncorrelated scaled normal pdf's for the diurnal curves of atmospheric ozone and VPD to best describe the ozone diffusion process for red spruce in the northeastern US. In addition, the model given in (3) simplifies for red spruce because $\mathrm{m}$ and $\nu_{2}$ are large enough that atmospheric ozone concentration and VPD do not approach those levels, at least for the six years of weather data we had from the period 1983 to 1990 . Hence, only the first two conditions given in (3) apply. Therefore, the expressions for $\mathrm{E}\left(\mathrm{Y}_{I} ; \theta\right)$ and $\operatorname{Var}\left(\mathrm{Y}_{I} ; \theta\right)$ simplify from those given in the Appendix but are still linear combinations of standard normal probabilities.

We investigated the relationship between estimated internal ozone dose (i.e., estimated internal ozone concentration) and atmospheric ozone concentration for the seasons from the three field sites at which red spruce were studied. For these data, we did not necessarily expect the relationship to be linear, and if a linear relationship was found, there were no a priori hypotheses about the magnitude of the slope since portion (3b) of the model might be operational. Figure 4 illustrates the relationship between estimated internal dose and atmospheric ozone concentration for the three sites; a scatterplot of the data is presented along with the reference line $y=x$, which corresponds to no adjustment. One feature is that the points for each site are clustered. The Whiteface Mountain values show the smallest downward adjustment even though they were largest. In Howland and Ithaca, internal doses were much less than atmospheric concentrations in all three years.

We also investigated the relationship between the estimated effective ozone dose and the applied ozone dose for red spruce grown in open-top chambers in Ithaca, NY during the 1987 and 1988 growing seasons. Four ozone doses, which were constant multiples of the ambient level (AOC) throughout the day (0.4, 1.0, 2.0 and 3.0 times AOC), were applied in each year (Amundson et al. 1990). The chambers for each dose were open to the atmosphere and, hence, the plants in different chambers were exposed to the same weather. The weather in the 1987 season was typical of the long-term average for Ithaca, whereas 1988 was very hot and dry with relatively high atmospheric ozone concentrations on many days. For each year all doses fall on a line because the doses were proportional and a common VPD adjustment (VPD measured outside of but adjacent to the chambers) was used for all the doses in that year. Using the uncorrelated model the 1987 data had a slope of $1.076 \pm 0.070$ whereas that for 
the 1988 data was $0.963 \pm 0.073$ (data not shown). The slopes were nearly unity, indicating that little adjustment from the applied dose was made in calculating the effective dose for either year. Since individual VPD measurements were not available, this data set is not a good test of the model.

\subsection{Hierarchical model for regional estimates}

A further goal in our modeling effort was to obtain regional estimators of the effective daily ozone dose for a species and the variance of that dose, which reflect the regional variation in the diurnal cycles of both atmospheric ozone concentration and VPD. Regional estimates like these would be useful to regulatory agencies in assessing the impact of ozone pollution on target species. This contrasts with the common practice of using atmospheric ozone concentrations from one or two particular sites that are deemed representative of a geographic region to indicate whether a species may be adversely impacted by ozone.

We approached this problem by embedding the basic model developed in Section 2.3 into a hierarchical model with random effects (Laird and Ware 1982; Casella 1985; Kass and Steffy 1989) to obtain a regional average effective dose and a regional variance of the dose. Essentially, we are compounding the distribution for internal ozone dose at a site with distributions for the variation in weather data among sites. The estimator of the variance of internal ozone dose thus obtained will necessarily be larger than the corresponding variance derived in Section 2.3. From the point of view of the hierarchical model, the $\operatorname{Var}\left(\mathrm{Y}_{I} ; \theta\right)$ from Section 2.3 (or its estimator) is conditional on site, explicitly on $\theta$, the parameters of the regression functions for the diurnal curves for atmospheric ozone concentration and VPD, and is obtained from the mixing distribution, $\mathrm{Y}_{I} \mid \theta$. The variance of $\mathrm{Y}_{I}$, $\operatorname{Var}\left(\mathrm{Y}_{I}\right)$, from the hierarchical model is based on the marginal distribution of $\mathrm{Y}_{I}$, which results from integrating over the distributions for the scale parameters of daily ozone concentration and daily VPD, necessarily producing a distribution for internal ozone dose with greater spread than the mixing distribution. An estimate of variance of internal dose based on the marginal distribution is more appropriate to report for regulatory purposes, since the estimate is relevant to an entire region and explicitly incorporates all variation in dose due to elevation, proximity to pollution sources, etc. within 
the geographic region.

In developing the hierarchical model for regional estimates, we put distributions only on the scale parameters of atmospheric ozone concentration and VPD diurnal cycles (the variance parameter if the normal or lognormal pdf was used or the scale parameter if the gamma pdf was used). For both ozone concentration and VPD in a given season, the time during the day at which the peak occurs (the location parameter) was relatively stable across sites within a geographic region. Hence, we did not put distributions on those parameters. Likewise, the baseline ozone concentration was similar for the days across sites and years that we investigated (ranged from 0.015 to $0.025 \mathrm{ppm}$ ). High elevation sites, such as Whiteface Mountain, may differ in baseline ozone from sites at lower elevations. However, no distribution was placed on the parameter for baseline ozone concentration. We modeled atmospheric ozone concentration and VPD as statistically independent and justify that choice as follows. Atmospheric ozone concentration and VPD were measured continuously throughout the day using different sensors. Due to the gas laws, the atmospheric ozone concentrations recorded are already corrected for the concurrent temperature and relative humidity, the components of VPD. Empirically, we found no statistically significant correlation between the diurnal curves of atmospheric ozone concentration and VPD, using data from several sites in the northeastern U.S. for several years. However, if one were uncomfortable with the independence assumption, one could use a bivariate distribution for the pair of scale parameters for the diurnal curves of ozone and VPD, which would result in a more complex hierarchical model than the one presented here.

We used the conjugate distributions for the scale parameters of the diurnal curves of atmospheric ozone concentration and VPD in setting up the hierarchical model. When the normal pdf was used as the regression function, we let $\sigma^{2}$ (or $\tau^{2}$ ), the variance parameter for daily ozone concentration (or daily VPD level) have an inverse gamma distribution:

$$
f\left(\sigma^{2}\right)=\frac{\eta^{q}}{\Gamma(\mathrm{q})}\left(\frac{1}{\sigma^{2}}\right)^{q+1} \exp \left(-\eta / \sigma^{2}\right)
$$

with parameters $\eta$ and $\mathrm{q}$ for $\sigma^{2}>0$ (or $\varphi$ and $\mathrm{s}$ for $\tau^{2}>0$ ). To calculate the expected regional daily effective dose, $\mathrm{E}\left(\mathrm{Y}_{I}\right)$, we integrated the product of $\mathrm{E}\left(\mathrm{Y}_{I} ; \theta\right)$ and the conjugate distributions for $\sigma^{2}$ and 
$\tau^{2}$ over the ranges of $\sigma^{2}$ and $\tau^{2}(0$ to $\infty)$. We proceeded similarly to obtain $\operatorname{Var}\left(\mathrm{Y}_{I}\right)$. With normal pdf's in (3) and inverse gamma distributions for $\sigma^{2}$ and $\tau^{2}$ we obtained a linear combination of integrals of the following form:

$$
\begin{aligned}
\int_{0}^{\infty} \Phi & ((\mathrm{t}-\theta) / \sigma)\left(\eta^{q} / \Gamma(\mathrm{q})\right)\left(1 / \sigma^{2}\right)^{q+1} \exp \left(-\eta / \sigma^{2}\right) \mathrm{d} \sigma^{2} \\
& =\Gamma((2 \mathrm{q}+1) / 2) /[\sqrt{2 \mathrm{q} \pi} \Gamma(2 \mathrm{q} / 2)] \int_{-\infty}^{\sqrt{q}(t-\theta) / \sqrt{\eta}} 1 /\left[1+\left(\mathrm{x}^{2} / 2 \mathrm{q}\right)\right]^{(2 q+1) / 2} \mathrm{dx} \\
& \equiv \mathrm{T}_{2 q}(\sqrt{\mathrm{q}}(\mathrm{t}-\theta) / \sqrt{\eta})
\end{aligned}
$$

where $\Phi(\cdot)$ is the standard normal cdf and $\mathrm{T}_{2 q}$ is a Student's t cdf with $2 \mathrm{q}$ degrees of freedom. Hence, when the expected daily dose is a linear combination of standard normal probabilities, the marginal expectation, the regional daily dose, is a linear combination of $t$ probabilities. Likewise, the variance of regional daily dose is a linear combination of $t$ probabilities. For the basic model with $f_{1}(t)$ and $\mathrm{f}_{2}(\mathrm{t})$ normal pdf's having mean and variance parameters $\left(\mu, \sigma^{2}\right)$ and $\left(\phi, \tau^{2}\right)$, respectively, and with $\sigma^{2}$ and $\tau^{2}$ having independent inverse gamma distributions with scale and shape parameters $(\eta, q)$ and $(\varphi, \mathrm{s})$, respectively, expressions for $\mathrm{E}\left(\mathrm{Y}_{I}\right)$ and $\operatorname{Var}\left(\mathrm{Y}_{I}\right)$, the regional expected dose and its variance, are obtained by substituting for each normal probability in the expressions for $\mathrm{E}\left(\mathrm{Y}_{I} ; \theta\right)$ and $\operatorname{Var}\left(\mathrm{Y}_{I} ; \theta\right)$ that are given in the Appendix, the Student's t probability from (13) with the appropriate parameters. Estimators of the mean and variance of regional daily internal ozone dose are obtained as in Section 2.3, by substituting the relevant estimates $\hat{\theta}$ from fitting the regressions for the diurnal curves of atmospheric ozone and VPD, the estimates for the parameters of the distributions and the speciesspecific constants into the expressions for $\mathrm{E}\left(\mathrm{Y}_{I}\right)$ and $\operatorname{Var}\left(\mathrm{Y}_{I}\right)$.

When the gamma pdf was used as the regression function for the diurnal curve of either ozone concentration or VPD, we let $\delta$, the scale parameter, have a gamma distribution:

$$
f(\delta)=\frac{\left(\alpha^{*}\right)^{\beta^{*}}}{\Gamma\left(\beta^{*}\right)} \delta^{\beta^{*}-1} \exp \left(-\alpha^{*} \delta\right),
$$

with scale and shape parameters, $\alpha^{*}$ and $\beta^{*}$, respectively, for $\delta>0$. In that case, the expected daily dose was a linear combination of gamma probabilities, and the corresponding regional daily dose was also a linear combination of gamma probabilities. The variance of regional daily dose in this case also 
is a linear combination of gamma probabilities. Suppose one were to use the gamma pdf for the regression function of daily ozone concentration or daily VPD in (3) but reparameterized the gamma pdf in terms of its mean and variance. Then, using an inverse gamma prior for the variance of daily ozone or VPD yields the expected regional internal ozone and its variance, but these now do not have closed form expressions. Hence, for the hierarchical model, it is preferable to use the gamma pdf's for $\mathrm{Y}_{A}(\mathrm{t})$ and $\mathrm{D}(\mathrm{t})$ having their conventional parameterization with scale and shape parameters.

\subsection{Sample calculation}

To illustrate the calculations for the basic and hierarchical models, we use the data for the 1988 growing season in Ithaca, NY with red spruce as the target species. For red spruce, the species-specific constants are $\nu_{1}=1.2 \mathrm{MPa}, \nu_{2}=1.8 \mathrm{MPa}, \mathrm{k}_{\mathrm{s}}=0.350 \mathrm{~cm} / \mathrm{sec}, \mathrm{k}_{\mathrm{c}}=0.075 \mathrm{~cm} / \mathrm{sec}$ and $\mathrm{m}=0.4 \mathrm{ppm}$. For the 1988 growing season in Ithaca, the parameter estimates for the diurnal curve for atmospheric ozone concentration were $\widehat{\alpha}=0.025, \widehat{\beta}=0.330, \widehat{\sigma}=4.332, \widehat{\mu}=10.446, \widehat{\eta}^{2}=0.000005$ and those for the diurnal curve for VPD were $\widehat{\kappa}=0.212, \widehat{\gamma}=\widehat{\lambda}=12.134$ (in practice we have found $\widehat{\lambda}=\widehat{\gamma}$ for a number of data sets), $\widehat{\tau}=3.727, \widehat{\phi}=9.118, \widehat{\omega}^{2}=0.0027$. Hence, the critical times (see Appendix) $\left(t_{1}, t_{2}\right)$ are $(6,12)$. Using the formulae in the Appendix, we found the daily expected internal dose, $24 \mathrm{E}\left(\mathrm{Y}_{I} ; \theta\right)$, to be 0.92 ppm with a standard deviation of $0.99 \mathrm{ppm}$.

For the hierarchical model we got crude method of moments estimates for the inverse gamma distribution giving $\widehat{\eta}=33.709, \widehat{\mathrm{q}}=2.542, \widehat{\varphi}=299.857$ and $\widehat{\mathrm{s}}=85.689$. These gave $24 \widehat{\mathrm{E}}\left[\mathrm{Y}_{I}\right]$ as $1.02 \mathrm{ppm}$ with a standard deviation of $0.92 \mathrm{ppm}$. The standard deviation was unexpectedly lower for the hierarchical model, because the typical values of $\sigma$ using $\widehat{\eta}=33.709$ and $\widehat{\mathrm{q}}=2.542$ are larger than the 4.332 value used for $\widehat{\sigma}$ in the 1988 Ithaca NY data (due to inclusion of high elevation sites like Whiteface Mountain). Hence the ozone curve is much flatter and less variable than the one observed for Ithaca in 1988.

\section{Discussion}

This paper develops a statistical model to estimate the ozone dose received by plant cells. Unlike previous work on ozone dose (Lett et al. 1991; Lefohn and Foley 1992; Tingey et al. 1991), this model 
incorporates the physiological processes (e.g., stomatal closure) that are responsible for causing the ozone concentration within the leaf to differ from the atmospheric concentration. Our model adjusts the atmospheric ozone concentration downward, especially for days with prolonged periods of high VPD. While all reasonable models adjust ozone downwards, ours is able to respond differentially according to ozone levels and VPD.

We also developed a hierarchical model which may be applied on a broad regional scale to adjust potential ozone response based on what is known about environmental conditions and the major vegetation types of a geographical area. For instance, such a model might be used within the framework proposed by Hogsett (personal communication) to modify effective ambient ozone concentrations that are used in exposure-response models within a geographic information system. Models which fail to incorporate variation in effective dose within a geographic region due to elevation, proximity to pollution sources, etc. will give misleading estimates of ozone impact on vegetation. Our model incorporates such variation through the mixing distributions.

While use of this method requires information about the physiology of the plant of interest, the data required to parameterize the model is readily available from the scientific literature. Furthermore, it may be possible to establish model parameters based on broad classifications of vegetation (such as those proposed by Grime 1977) for use in species-independent regional application. Although we have used the model only to adjust ozone concentration by VPD, we believe it will work as well for other environmental factors that might alter the uptake of ozone by the plant.

\section{Acknowledgment}

The authors gratefully acknowledge helpful discussions about this work with Sir D.R. Cox and Drs. R. Wayne, R.A. Amundson, and G. Casella and the detailed reading by the referees. 


\section{APPENDIX: Exact Formulae for the Unconditional Mean and Variance of Internal Ozone Concentration Under the Normal Model}

In this Appendix we list the formulae for $\mathrm{E}\left(\mathrm{Y}_{I} ; \theta\right)$ and $\operatorname{Var}\left(\mathrm{Y}_{I} ; \theta\right)$ when the regression functions for ambient ozone concentration and VPD, $f_{1}(t)$ and $f_{2}(t)$, are normal pdf's with mean and variance

parameters $\left(\mu, \sigma^{2}\right)$ and $\left(\phi, \tau^{2}\right)$, respectively, and $\operatorname{Cov}(\epsilon, \zeta)=\rho \omega \eta$ (see equation (3)). In this case, both $\mathrm{E}\left(\mathrm{Y}_{I} ; \theta\right)$ and $\operatorname{Var}\left(\mathrm{Y}_{I} ; \theta\right)$ are linear combinations of normal probabilities. The crucial feature of these calculations is that the definite integral of the product of two normal pdf's is equal to a standard normal probability times a constant, as are the definite integral of the product of the squares of two normal pdf's and the definite integral of the product of a normal pdf and the square of another normal pdf. For simplicity of notation, the dependence on $\theta$ is suppressed in most of the expressions given below.

To conveniently derive $\mathrm{E}\left(\mathrm{Y}_{I} ; \theta\right)$ and $\operatorname{Var}\left(\mathrm{Y}_{I} ; \theta\right)$ in this special case, we need additional notation to denote the integration of the components of the conditional moments over the appropriate time intervals. We can convert the conditions $\mathrm{D}(\mathrm{t})$ and $\mathrm{Y}_{A}(\mathrm{t})$ in the model to partitions of time (Figure 5). The intersections of the lines $\mathrm{D}(\mathrm{t})=\nu_{1}$ and $\mathrm{D}(\mathrm{t})=\nu_{2}$ with the diurnal curve for VPD yield the critical times $t_{1}, t_{6}$ and $t_{2}, t_{5}$, respectively. Likewise, the intersection of the line $Y_{A}(t)=m$ with the diurnal curve for atmospheric ozone concentration defines the critical times $t_{3}, t_{4}$. This set of critical times defines seven partitions of the time axis, which is the 24-hour day:

$$
\begin{gathered}
\mathrm{I}_{1}(\mathrm{t})=\left\{\mathrm{t} \epsilon\left[0, \mathrm{t}_{1}\right)\right\}, \quad \mathrm{I}_{2}(\mathrm{t})=\left\{\mathrm{t} \epsilon\left(\mathrm{t}_{6}, 24\right]\right\}, \quad \mathrm{I}_{3}(\mathrm{t})=\left\{\mathrm{t} \epsilon\left[\mathrm{t}_{2}, \mathrm{t}_{3}\right)\right\}, \quad \mathrm{I}_{4}(\mathrm{t})=\left\{\mathrm{t} \epsilon\left(\mathrm{t}_{4}, \mathrm{t}_{5}\right]\right\} \\
\mathrm{I}_{5}(\mathrm{t})=\left\{\mathrm{t} \epsilon\left[\mathrm{t}_{3}, \mathrm{t}_{4}\right)\right\}, \quad \mathrm{I}_{6}(\mathrm{t})=\left\{\mathrm{t} \epsilon\left[\mathrm{t}_{1}, \mathrm{t}_{2}\right)\right\}, \quad \mathrm{I}_{7}(\mathrm{t})=\left\{\mathrm{t} \epsilon\left(\mathrm{t}_{5}, \mathrm{t}_{6}\right]\right\}
\end{gathered}
$$

For example, based on the schematic curves in Figure 5, the set of conditions on $\mathrm{Y}_{A}(\mathrm{t})$ and $\mathrm{D}(\mathrm{t})$ given in (3a) are equivalent to $t \epsilon\left\{\mathrm{I}_{1}(\mathrm{t}), \mathrm{I}_{2}(\mathrm{t})\right\}$ :

$$
\mathrm{Y}_{A}(\mathrm{t})<\mathrm{m}, 0 \leq \mathrm{D}(\mathrm{t})<\nu_{1} \Leftrightarrow 0<\mathrm{t}<\mathrm{t}_{1}, \mathrm{t}_{\mathrm{G}}<\mathrm{t} \leq 24 .
$$

Similarly, the other conditions on $\mathrm{D}(\mathrm{t})$ and $\mathrm{Y}_{A}(\mathrm{t})$ can be converted to partitions of time. $\mathrm{I}_{6}(\mathrm{t})$ and $I_{7}(t)$ are the time intervals during which the internal ozone concentration is discounted from ambient due to the VPD effects on stomatal closure. $I_{3}(t), I_{4}(t)$ and $I_{5}(t)$ are time intervals during which the 
internal ozone concentration would be low, since the stomata are closed and the internal concentration is determined by diffusion across the cuticle.

Let $\mathrm{E}_{r}(\cdot)$ denote expectation over a time interval $\mathrm{I}_{r}(\mathrm{t})=\left\{\mathrm{t} \epsilon\left(\mathrm{t}_{i}, \mathrm{t}_{j}\right)\right\}$ of a random variable conditional on time, $\mathrm{E}(\mathrm{X} \mid \mathrm{t})$, say. For example,

$$
\mathrm{E}_{r}\left(\mu_{Y_{A}}\right)=\mathrm{E}_{r}\left[\mathrm{E}\left(\mathrm{Y}_{A} \mid \mathrm{t}\right)\right]=\mathrm{E}_{r}\left[\alpha+\beta \mathrm{f}_{1}(\mathrm{t})\right]=\int_{t_{i}}^{t_{j}}\left[\alpha+\beta \mathrm{f}_{1}(\mathrm{t})\right](1 / 24) \mathrm{dt}
$$

Similarly, one can subscript variance and covariance operators to indicate the regions of integration that define the components of the unconditional variances and covariances. Using this notation, with $\Phi(\cdot)$ the standard normal cdf,

$$
\mathrm{E}_{r}\left[\alpha+\beta \mathrm{f}_{1}(\mathrm{t})\right]=(\alpha / 24)\left(\mathrm{t}_{j}-\mathrm{t}_{i}\right)+(\beta / 24)\left[\Phi\left(\left(\mathrm{t}_{j}-\mu\right) / \sigma\right)-\Phi\left(\left(\mathrm{t}_{i}-\mu\right) / \sigma\right)\right]
$$

and

$$
\mathrm{E}_{r}\left[\kappa+\gamma \mathrm{f}_{2}(\mathrm{t})\right]=(\kappa / 24)\left(\mathrm{t}_{j}-\mathrm{t}_{i}\right)+(\gamma / 24)\left[\Phi\left(\left(\mathrm{t}_{j}-\phi\right) / \tau\right)-\Phi\left(\left(\mathrm{t}_{i}-\phi\right) / \tau\right)\right]
$$

We also need the expectation of the cross-product $\mu_{Y_{A}} \mu_{D}$, which requires

$$
\begin{aligned}
& \int_{t_{i}}^{t_{j}} \mathrm{f}_{1}(\mathrm{t}) \mathrm{f}_{2}(\mathrm{t})(1 / 24) \mathrm{dt} \\
& \quad=\left[1 /\left(24 \sqrt{2 \pi} \sqrt{\sigma^{2}+\tau^{2}}\right)\right] \exp \left\{-(\mu-\phi)^{2} /\left[2\left(\sigma^{2}+\tau^{2}\right)\right]\right\}\left[\Phi\left(\left(\mathrm{t}_{j}-\mu_{1}\right) / \sigma_{1}^{*}\right)-\Phi\left(\left(\mathrm{t}_{i}-\mu_{1}\right) / \sigma_{1}^{*}\right)\right],
\end{aligned}
$$

where $\mu_{1}=\left(\mu \tau^{2}+\phi \sigma^{2}\right) /\left(\sigma^{2}+\tau^{2}\right)$ and $\sigma_{1}^{*}=\sigma \tau / \sqrt{\sigma^{2}+\tau^{2}}$. Thus,

$$
\begin{aligned}
& \mathrm{E}_{r}\left(\left[\alpha+\beta \mathrm{f}_{1}(\mathrm{t})\right]\left[\kappa+\gamma \mathrm{f}_{2}(\mathrm{t})\right]\right) \\
& \quad=(1 / 24)\left\{\alpha \kappa\left(\mathrm{t}_{j}-\mathrm{t}_{i}\right)+\kappa \beta\left[\Phi\left(\left(\mathrm{t}_{j}-\mu\right) / \sigma\right)-\Phi\left(\left(\mathrm{t}_{i}-\mu\right) / \sigma\right)\right]+\alpha \gamma\left[\Phi\left(\left(\mathrm{t}_{j}-\phi\right) / \tau\right)-\Phi\left(\left(\mathrm{t}_{i}-\phi\right) / \tau\right)\right]\right. \\
& \left.\quad+\left[\beta \gamma /\left(24 \sqrt{2 \pi} \sqrt{\sigma^{2}+\tau^{2}}\right)\right] \exp \left\{-(\mu-\phi)^{2} /\left[2\left(\sigma^{2}+\tau^{2}\right)\right]\right\}\left[\Phi\left(\left(\mathrm{t}_{j}-\mu_{1}\right) / \sigma_{1}^{*}\right)-\Phi\left(\left(\mathrm{t}_{i}-\mu_{1}\right) / \sigma_{1}^{*}\right)\right]\right\} .
\end{aligned}
$$




\section{From equation (9)}

$$
\begin{aligned}
\mathrm{E}\left(\mathrm{Y}_{I} ;\right. & \theta)=\int_{0}^{t_{1}}\left[\alpha+\beta \mathrm{f}_{1}(\mathrm{t})\right](1 / 24) \mathrm{dt}+\int_{t_{6}}^{24}\left[\alpha+\beta \mathrm{f}_{1}(\mathrm{t})\right](1 / 24) \mathrm{dt} \\
& +\left[\mathrm{k}_{c} /\left(\mathrm{k}_{s}+\mathrm{k}_{c}\right)\right] \int_{t_{2}}^{t_{5}}\left[\alpha+\beta \mathrm{f}_{1}(\mathrm{t})\right](1 / 24) \mathrm{dt}-(1 / \mathrm{c}) \rho \omega \eta\left[\left(\mathrm{t}_{2}-\mathrm{t}_{1}+\mathrm{t}_{6}-\mathrm{t}_{5}\right) / 24\right] \\
& +\left[1+\left(\nu_{1} / \mathrm{c}\right)\right] \int_{t_{1}}^{t_{2}}\left[\alpha+\beta \mathrm{f}_{1}(\mathrm{t})\right](1 / 24) \mathrm{dt}-(1 / \mathrm{c}) \int_{t_{1}}^{t_{2}}\left[\alpha+\beta \mathrm{f}_{1}(\mathrm{t})\right]\left[\kappa+\gamma \mathrm{f}_{2}(\mathrm{t})\right](1 / 24) \mathrm{dt} \\
& +\left[1+\left(\nu_{1} / \mathrm{c}\right)\right] \int_{t_{5}}^{t_{6}}\left[\alpha+\beta \mathrm{f}_{1}(\mathrm{t})\right](1 / 24) \mathrm{dt}-(1 / \mathrm{c}) \int_{t_{5}}^{t_{6}}\left[\alpha+\beta \mathrm{f}_{1}(\mathrm{t})\right]\left[\kappa+\gamma \mathrm{f}_{2}(\mathrm{t})\right](1 / 24) \mathrm{dt},
\end{aligned}
$$

where $c=\lambda\left(\nu_{2}-v_{1}\right)$. Substituting (A1) $-(\mathrm{A} 3)$ for the appropriate intervals into (9) gives $E\left(\mathrm{Y}_{I} ; \theta\right)$ equal to

$$
\begin{aligned}
(\alpha / 24) & \left(24-\mathrm{t}_{6}+\mathrm{t}_{1}\right)+(\beta / 24)\left[\Phi\left(\left(\mathrm{t}_{1}-\mu\right) / \sigma\right)-\Phi(-\mu / \sigma)+\Phi((24-\mu) / \sigma)-\Phi\left(\left(\mathrm{t}_{6}-\mu\right) / \sigma\right)\right] \\
& +\left[\mathrm{k}_{c} /\left(\mathrm{k}_{s}+\mathrm{k}_{c}\right)\right](\alpha / 24)\left(\mathrm{t}_{5}-\mathrm{t}_{2}\right)+\left[\mathrm{k}_{c} /\left(\mathrm{k}_{s}+\mathrm{k}_{c}\right)\right](\beta / 24)\left[\Phi\left(\left(\mathrm{t}_{5}-\mu\right) / \sigma\right)-\Phi\left(\left(\mathrm{t}_{2}-\mu\right) / \sigma\right)\right] \\
& +\left[1+\left(\nu_{1} / \mathrm{c}\right)\right]\left\{(\alpha / 24)\left(\mathrm{t}_{2}-\mathrm{t}_{1}\right)+(\beta / 24)\left[\Phi\left(\left(\mathrm{t}_{2}-\mu\right) / \sigma\right)-\Phi\left(\left(\mathrm{t}_{1}-\mu\right) / \sigma\right)\right]\right\} \\
& -(1 / 24 \mathrm{c})\left\{\alpha \kappa\left(\mathrm{t}_{2}-\mathrm{t}_{1}\right)+\kappa \beta\left[\Phi\left(\left(\mathrm{t}_{2}-\mu\right) / \sigma\right)-\Phi\left(\left(\mathrm{t}_{1}-\mu\right) / \sigma\right)\right]+\alpha \gamma\left[\Phi\left(\left(\mathrm{t}_{2}-\phi\right) / \tau\right)-\Phi\left(\left(\mathrm{t}_{1}-\phi\right) / \tau\right)\right]\right. \\
& \left.+\left[\beta \gamma /\left(24 \sqrt{2 \pi} \sqrt{\sigma^{2}+\tau^{2}}\right)\right] \exp \left\{-(\mu-\phi)^{2} /\left[2\left(\sigma^{2}+\tau^{2}\right)\right]\right\}\left[\Phi\left(\left(\mathrm{t}_{2}-\mu_{1}\right) / \sigma_{1}^{*}\right)-\Phi\left(\left(\mathrm{t}_{1}-\mu_{1}\right) / \sigma_{1}^{*}\right)\right]\right\} \\
& +\left[1+\left(\nu_{1} / \mathrm{c}\right)\right]\left\{(\alpha / 24)\left(\mathrm{t}_{6}-\mathrm{t}_{5}\right)+(\beta / 24)\left[\Phi\left(\left(\mathrm{t}_{6}-\mu\right) / \sigma\right)-\Phi\left(\left(\mathrm{t}_{5}-\mu\right) / \sigma\right)\right]\right\} \\
& -(1 / 24 \mathrm{c})\left\{\alpha \kappa\left(\mathrm{t}_{6}-\mathrm{t}_{5}\right)+\kappa \beta\left[\Phi\left(\left(\mathrm{t}_{6}-\mu\right) / \sigma\right)-\Phi\left(\left(\mathrm{t}_{5}-\mu\right) / \sigma\right)\right]+\alpha \gamma\left[\Phi\left(\left(\mathrm{t}_{6}-\phi\right) / \tau\right)-\Phi\left(\left(\mathrm{t}_{5}-\phi\right) / \tau\right)\right]\right. \\
+ & {\left.\left[\beta \gamma /\left(24 \sqrt{2 \pi} \sqrt{\sigma^{2}+\tau^{2}}\right)\right] \exp \left\{-(\mu-\phi)^{2} /\left[2\left(\sigma^{2}+\tau^{2}\right)\right]\right\}\left[\Phi\left(\left(\mathrm{t}_{6}-\mu_{1}\right) / \sigma_{1}^{*}\right)-\Phi\left(\left(\mathrm{t}_{5}-\mu_{1}\right) / \sigma_{1}^{*}\right)\right]\right\} } \\
& -(1 / \mathrm{c}) \rho \omega \eta\left(\mathrm{t}_{6}-\mathrm{t}_{5}+\mathrm{t}_{2}-\mathrm{t}_{1}\right) / 24 .
\end{aligned}
$$

The unconditional variance of the internal ozone concentration is

$$
\operatorname{Var}\left(\mathrm{Y}_{i} ; \theta\right)=\operatorname{Var}_{t}\left[\mathrm{E}\left(\mathrm{Y}_{i} \mid \mathrm{t} ; \theta\right)\right]+\mathrm{F}_{i}\left[\operatorname{Var}\left(\underline{Y}_{i} \mid t ; \theta\right)\right]
$$

General expressions for $\operatorname{Var}_{t}\left[\mathrm{E}\left(\mathrm{Y}_{I} \mid \mathrm{t} ; \theta\right)\right]$ and $\mathrm{E}_{t}\left[\operatorname{Var}\left(\mathrm{Y}_{I} \mid \mathrm{t} ; \theta\right)\right]$ are given in (11) and (12). To substitute into these expressions, we need some variance terms and expectations of higher order crossproducts in addition to $(\mathrm{A} 1)-(\mathrm{A} 3)$. To derive these higher order terms we require the following: 


$$
\begin{array}{r}
\int_{t_{i}}^{t_{j}}\left[\mathrm{f}_{1}(\mathrm{t})\right]^{2}(1 / 24) \mathrm{dt}=[1 /(48 \sigma \sqrt{\pi})]\left[\Phi\left(\sqrt{2}\left(\mathrm{t}_{j}-\mu\right) / \sigma\right)-\Phi\left(\sqrt{2}\left(\mathrm{t}_{i}-\mu\right) / \sigma\right)\right], \\
\int_{t_{i}}^{t_{j}}\left[\mathrm{f}_{2}(\mathrm{t})\right]^{2}(1 / 24) \mathrm{dt}=[1 /(48 \tau \sqrt{\pi})]\left[\Phi\left(\sqrt{2}\left(\mathrm{t}_{j}-\phi\right) / \tau\right)-\Phi\left(\sqrt{2}\left(\mathrm{t}_{i}-\phi\right) / \tau\right)\right], \\
\int_{t_{i}}^{t_{j}}\left[\mathrm{f}_{1}(\mathrm{t})\right]^{2} \mathrm{f}_{2}(\mathrm{t})(1 / 24) \mathrm{dt}=\left[1 /\left(24 \sqrt{2 \pi} \sqrt{\sigma^{2}+\tau^{2}}\right)\right] \exp \left\{-(\mu-\phi)^{2} /\left[2\left(\sigma^{2}+\tau^{2}\right)\right]\right\} \\
\times\left[\Phi\left(\left(\mathrm{t}_{j}-\mu_{2}\right) / \sigma_{2}^{*}\right)-\Phi\left(\left(\mathrm{t}_{i}-\mu_{2}\right) / \sigma_{2}^{*}\right)\right],
\end{array}
$$

where $\mu_{2}=\left(2 \theta \tau^{2}+\phi \sigma^{2}\right) /\left(\sigma^{2}+2 \tau^{2}\right)$ and $\sigma_{2}^{*}=\sigma \tau / \sqrt{\sigma^{2}+2 \tau^{2}}$,

$$
\begin{array}{r}
\int_{t_{i}}^{t_{j}} \mathrm{f}_{1}(\mathrm{t})\left[\mathrm{f}_{2}(\mathrm{t})\right]^{2}(1 / 24) \mathrm{dt}=\left[1 /\left(24 \sqrt{2 \pi} \sqrt{2 \sigma^{2}+\tau^{2}}\right)\right] \exp \left\{-(\mu-\phi)^{2} /\left[2\left(2 \sigma^{2}+\tau^{2}\right)\right]\right\} \\
\times\left[\Phi\left(\left(\mathrm{t}_{j}-\mu_{3}\right) / \sigma_{3}^{*}\right)-\Phi\left(\left(\mathrm{t}_{i}-\mu_{3}\right) / \sigma_{3}^{*}\right)\right]
\end{array}
$$

where $\mu_{3}=\left(\theta \tau^{2}+2 \phi \sigma^{2}\right) /\left(2 \sigma^{2}+\tau^{2}\right)$ and $\sigma_{3}^{*}=\sigma \tau / \sqrt{2 \sigma^{2}+\tau^{2}}$

$$
\begin{array}{r}
\int_{t_{i}}^{t_{j}}\left[\mathrm{f}_{1}(\mathrm{t})\right]^{2}\left[\mathrm{f}_{2}(\mathrm{t})\right]^{2}(1 / 24) \mathrm{dt}=\left[1 /\left(96 \pi^{3 / 2} \sigma \tau \sqrt{\sigma^{2}+\tau^{2}}\right)\right] \exp \left\{-(\mu-\phi)^{2} /\left(\sigma^{2}+\tau^{2}\right)\right\} \\
\times\left[\Phi\left(\sqrt{2}\left(\mathrm{t}_{j}-\mu_{1}\right) / \sigma_{1}^{*}\right)-\Phi\left(\sqrt{2}\left(\mathrm{t}_{i}-\mu_{1}\right) / \sigma_{1}^{*}\right)\right] .
\end{array}
$$

Using these expressions, we can derive the components of $\mathrm{E}_{t}\left[\operatorname{Var}\left(\mathrm{Y}_{I} \mid \mathrm{t} ; \theta\right)\right]$ and $\operatorname{Var}_{t}\left[\mathrm{E}\left(\mathrm{Y}_{I} \mid \mathrm{t} ; \theta\right)\right]$. Using (A4) and the definition of the variance of a random variable, we find

$$
\begin{aligned}
\operatorname{Var}_{r}\left(\mu_{Y_{A}}\right) & =\mathrm{E}_{r}\left(\left[\alpha+\beta \mathrm{f}_{1}(\mathrm{t})\right]^{2}\right)-\left(\mathrm{E}_{r}\left[\alpha+\beta \mathrm{f}_{1}(\mathrm{t})\right]\right)^{2} \\
& =\left(\alpha^{2} / 24\right)\left(\mathrm{t}_{j}-\mathrm{t}_{i}\right)\left[1-\left(\mathrm{t}_{j}-\mathrm{t}_{i}\right) / 24\right]+2(\alpha \beta / 24)\left[\Phi\left(\left(\mathrm{t}_{j}-\mu\right) / \sigma\right)-\Phi\left(\left(\mathrm{t}_{i}-\mu\right) / \sigma\right)\right]\left[1-\left(\mathrm{t}_{j}-\mathrm{t}_{i}\right) / 24\right] \\
& +\left(\beta^{2} / 48 \sigma \sqrt{\pi}\right)\left[\Phi\left(\sqrt{2}\left(\mathrm{t}_{j}-\mu\right) / \sigma\right)-\Phi\left(\sqrt{2}\left(\mathrm{t}_{i}-\mu\right) / \sigma\right)\right]-(\beta / 24)^{2}\left[\Phi\left(\left(\mathrm{t}_{j}-\mu\right) / \sigma\right)-\Phi\left(\left(\mathrm{t}_{i}-\mu\right) / \sigma\right)\right]^{2}
\end{aligned}
$$

Similarly, using (A5);

$$
\begin{aligned}
\operatorname{Var}_{r}\left(\mu_{D}\right) & =\mathrm{E}_{r}\left(\left[\kappa+\gamma \mathrm{f}_{2}(\mathrm{t})\right]^{2}\right)-\left(\mathrm{E}_{r}\left[\kappa+\gamma \mathrm{f}_{2}(\mathrm{t})\right]\right)^{2} \\
& =\left(\kappa^{2} / 24\right)\left(\mathrm{t}_{j}-\mathrm{t}_{i}\right)\left[1-\left(\mathrm{t}_{j}-\mathrm{t}_{i}\right) / 24\right]+2(\kappa \gamma / 24)\left[\Phi\left(\left(\mathrm{t}_{j}-\phi\right) / \tau\right)-\Phi\left(\left(\mathrm{t}_{i}-\phi\right) / \tau\right)\right]\left[1-\left(\mathrm{t}_{j}-\mathrm{t}_{i}\right) / 24\right] \\
& +\left(\gamma^{2} / 48 \tau \sqrt{\pi}\right)\left[\Phi\left(\sqrt{2}\left(\mathrm{t}_{j}-\phi\right) / \tau\right)-\Phi\left(\sqrt{2}\left(\mathrm{t}_{i}-\phi\right) / \tau\right)\right]-(\gamma / 24)^{2}\left[\Phi\left(\left(\mathrm{t}_{j}-\phi\right) / \tau\right)-\Phi\left(\left(\mathrm{t}_{i}-\phi\right) / \tau\right)\right]^{2} .
\end{aligned}
$$


Using (A1) - (A3), (A9) and (A10) with (12) yields $\mathrm{E}_{t}\left[\operatorname{Var}\left(\mathrm{Y}_{I} \mid \mathrm{t} ; \theta\right)\right]$. A portion of $\operatorname{Var}_{t}\left[\mathrm{E}\left(\mathrm{Y}_{I} \mid \mathrm{t} ; \theta\right)\right]$ given in (11) corresponds to the $\operatorname{Var}_{r}\left(\mu_{Y_{A}}\left[1+\left(\nu_{1} / c\right)-(1 / c) \mu_{D}\right]\right)$, which equals

$$
\begin{aligned}
\mathrm{E}_{r}\left(\mu_{Y_{A}}^{2}\left[1+\left(\nu_{1} / \mathrm{c}\right)-(1 / \mathrm{c}) \mu_{D}\right]^{2}\right)-\left[\mathrm{E}_{r}\left(\mu_{Y_{A}}\left[1+\left(\nu_{1} / \mathrm{c}\right)-(1 / \mathrm{c}) \mu_{D}\right]\right)\right]^{2} \\
=\left[1+\left(\nu_{1} / \mathrm{c}\right)\right]^{2} \mathrm{E}_{r}\left(\mu_{Y_{A}}^{2}\right)-2(1 / \mathrm{c})\left[1+\left(\nu_{1} / \mathrm{c}\right)\right] \mathrm{E}_{r}\left(\mu_{Y_{A}}^{2} \mu_{D}\right)+(1 / \mathrm{c})^{2} \mathrm{E}_{r}\left(\mu_{Y_{A}}^{2} \mu_{D}^{2}\right) \\
-\left[1+\left(\nu_{1} / \mathrm{c}\right)\right]^{2}\left[\mathrm{E}_{r}\left(\mu_{Y_{A}}\right)\right]^{2}+2(1 / \mathrm{c})\left[1+\left(\nu_{1} / \mathrm{c}\right)\right] \mathrm{E}_{r}\left(\mu_{Y_{A}}\right) \mathrm{E}_{r}\left(\mu_{Y_{A}} \mu_{D}\right) \\
-(1 / \mathrm{c})^{2}\left[\mathrm{E}_{r}\left(\mu_{Y_{A}} \mu_{D}\right)\right]^{2},
\end{aligned}
$$

where $\mu_{Y_{A}}=\alpha+\beta \mathrm{f}_{1}(\mathrm{t})$ and $\mu_{D}=\kappa+\gamma \mathrm{f}_{1}(\mathrm{t})$. The expressions for $\mathrm{E}_{r}\left(\mu_{Y_{A}}^{2} \mu_{D}\right)$ and $\mathrm{E}_{r}\left(\mu_{Y_{A}}^{2} \mu_{D}^{2}\right)$ require (A6) -(A8). Substituting (A1) to (A8) into (11), after expanding the squared expressions in each integral, yields $\operatorname{Var}_{t}\left[\mathrm{E}\left(\mathrm{Y}_{I} \mid \mathrm{t} ; \theta\right)\right]$. 


\section{References}

Amundson, R. G., Hadley, J. L., Fincher, J. F., Fellows, S., and Alscher, R. G. (1992) Comparisons of seasonal changes in photosynthetic capacity, pigments, and carbohydrates of healthy sapling and mature red spruce and of declining and healthy red spruce. Canadian Journal of Forest Research 22, 1605-1616.

Casella, G. (1985) An introduction to empirical Bayes data analysis. The American Statistician 39, 83-87.

Cure, W. W., Sanders, J. S., and Heagle, A. S. (1986) Crop yield response predicted with different characterizations of the same ozone treatments. Journal of Environmental Quality 15, 251-254.

Fincher, J., Cumming, J. R., Alscher, R. G., Rubin, G., and Weinstein, L. (1989) Long-term ozone exposure affects winter hardiness of red spruce seedlings. New Phytologist 113, 85-96.

Grime, J. P. (1977) Evidence for the existence of three primary strategies in plants and its relevance to ecological and evolutionary theory. American Naturalist 111, 1168-1194.

Kass, R. E. and Steffy, D. (1989) Approximate Bayesian inference in conditionally independent hierarchical models (parametric empirical Bayes models) Journal of the American Statistical Association 84, 717-726.

Kohut, R. J., Amundson, R. G., Laurence, J. A., Colavito, L., van Leuken, P., and King, P. (1987) Effects of ozone and sulfur dioxide on the yield of winter wheat. Phytopathology 77, 71-74.

Krupa, S. V. and Nosai, M. (1989) Effects of ozone on agricultural crops. In Atmospheric Ozone Research and Its Policy Implications, ed. T. Schneider, Amsterdam: Elsevier Science Publishers, pp. 229-238.

Laird, N. M. and Ware, J. H. (1982) Random-effects models for longitudinal data. Biometrics 38, 963-974.

Larsen, R. I. and Heck, W. W. (1976) An air quality data analysis system for interrelating effects, standards, and needed source reduction. Part 3: Vegetation injury. Journal of Air Pollution Control Association 26, 325-333. 
Lee, E. H., Hogsett, W. E., and Tingey, D. T. (1991) Efficacy of ozone exposure indices in the standard setting process. In Tropospheric Ozone and the Environment, eds. R. L. Berglund, D. R. Lawson and D. J. McKee, Pittsburgh, Pennsylvania: Air \& Waste Management Association, Transaction No. 19, pp. 255-271.

Lefohn, A. S. and Foley, J. K. (1992) NCLAN results and their application to the standard-setting process: protecting vegetation from surface ozone exposures. Journal of Air Waste Management Association, 42, 1046-1052.

Lefohn, A. S., Laurence, J. A., and Kohut, R. J. (1988) A comparison of indices that describe the relationship between exposure to ozone and reduction in the yield of agricultural crops. Atmospheric Environment 22, 1229-1240.

Lefohn, A. S. and Runeckles, V. C. (1987) Establishing standards to protect vegetation-ozone exposure/dose considerations. Atmospheric Environment 21, 561-568.

MacDowall, F. D. H., Mukammal, E. I., and Cole, A. F. W. (1964) Direct correlation of air polluting ozone and tobacco weather fleck. Canadian Journal of Plant Science 44, 410-417.

Nobel, P. S. (1991) Physicochemical and Environmental Plant Physiology. San Diego, California: Academic Press, Inc.

Oshima, R. J., Poe, M. P., Braegelmann, P. K., Balswin, D. W., and Van Way, V. (1976) Ozone dosage-crop loss function for alfalfa: A standardized method for assessing crop losses from air pollution. Journal of Air Pollution Control Association 26, 861-865.

Runeckles, V. C. and Chevone, B. I. (1992) Crop responses to ozone. In Surface Level Ozone Exposures and Their Effects on Vegetation, ed. A. S. Lefohn, Chelsea, Michigan: Lewis Publishers, pp. 189-270.

Tingey, D. T., Hogsett, W. E., and Henderson, S. (1990) Definition of adverse effects for the purpose of establishing secondary National Ambient Air Quality Standards. Journal of Environmental Quality 19, 635-639. 
Tingey, D. T., Hogsett, W. E., Lee, E. H., Herstrom, A. A., and Azevedo, S. H. (1991) An evaluation of various alternative ambient ozone standards based on crop yield loss data. In Tropospheric Ozone and the Environment, eds. R. L. Berglund, D. R. Lawson and D. J. McKee, Pittsburgh, Pennsylvania: Air \& Waste Management Association, Transaction No. 19, pp. 272-288.

U. S. Environmental Protection Agency. (1986) Air quality criteria for ozone and other photochemical oxidants. USEPA Rep. 600/8-84-020, Research Triangle Park, North Carolina: Environmental Criteria and Assessment Office.

U. S. Environmental Protection Agency. (1994) Air quality criteria for ozone and other photochemical oxidants. USEPA Rep. 600/8-84-020, Research Triangle Park, North Carolina: Environmental Criteria and Assessment Office. (In press.) 


\section{Figure Legends}

Figure 1. Winter needle damage measured as the natural logarithm of the number of brown needle clusters and standard errors as a function of applied ozone dose. The ozone doses were applied continuously as multiples of the ambient ozone concentration $(0.4,1,2$ and $3 \times$ ambient zone concentration). Ambient ozone averaged $0.04 \mathrm{ppm}$ between $8 \mathrm{am}$ and $8 \mathrm{pm}$ over the growing season.

Figure 2. The diurnal curves of ambient ozone concentration (A) and vapor pressure deficit (B) for an individual day in June, 1987 in Ithaca, NY. The smooth curve in each panel is the fitted normal curve. Time is measured in hours with time zero being $6 \mathrm{am}$ (sunrise).

Figure 3. The seasonal diurnal curve for ambient ozone concentration (A) and vapor pressure deficit (B) in 1988 in Ithaca, NY (ם), Howland, ME $(\mathbf{\Delta})$ and Whiteface Mountain, NY (•). The smooth curves are the fitted normal curves for each site. Time is measured in hours with time zero being $6 \mathrm{am}$ (sunrise).

Figure 4. The relationship between effective daily ozone dose and the daily atmospheric ozone concentration for the three field sites (Ithaca, NY $(\Delta)$; Howland, ME (X); Whiteface Mountain, NY (प)). Effective daily ozone dose is the estimated internal ozone concentration. The solid reference line represents $\mathrm{y}=\mathrm{x}$, for which both the estimated internal and atmospheric ozone concentrations would be equal.

Figure 5. Schematic diagram showing the conversion of the conditions on vapor pressure deficit and atmospheric ozone concentration to partitions of time. 


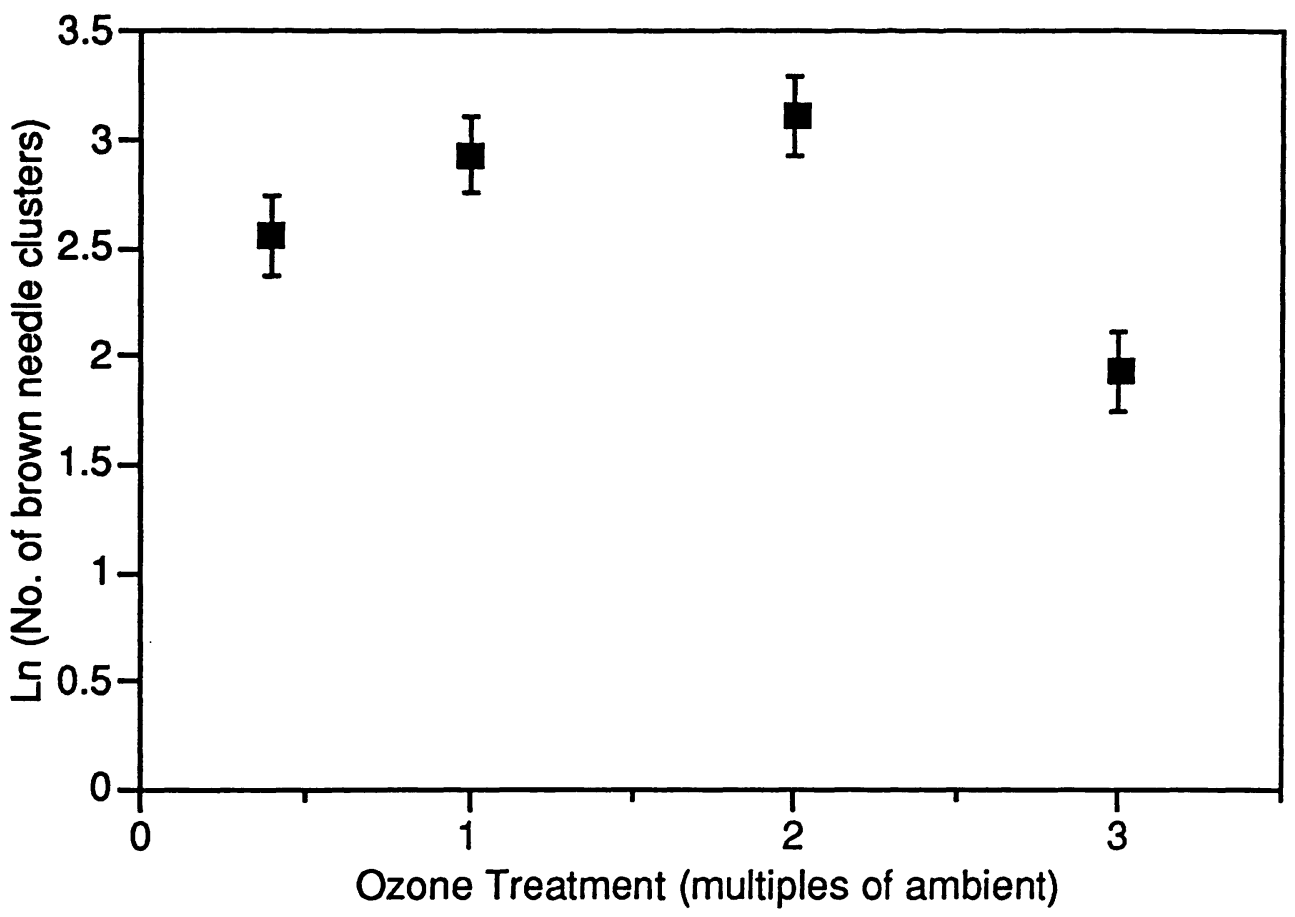



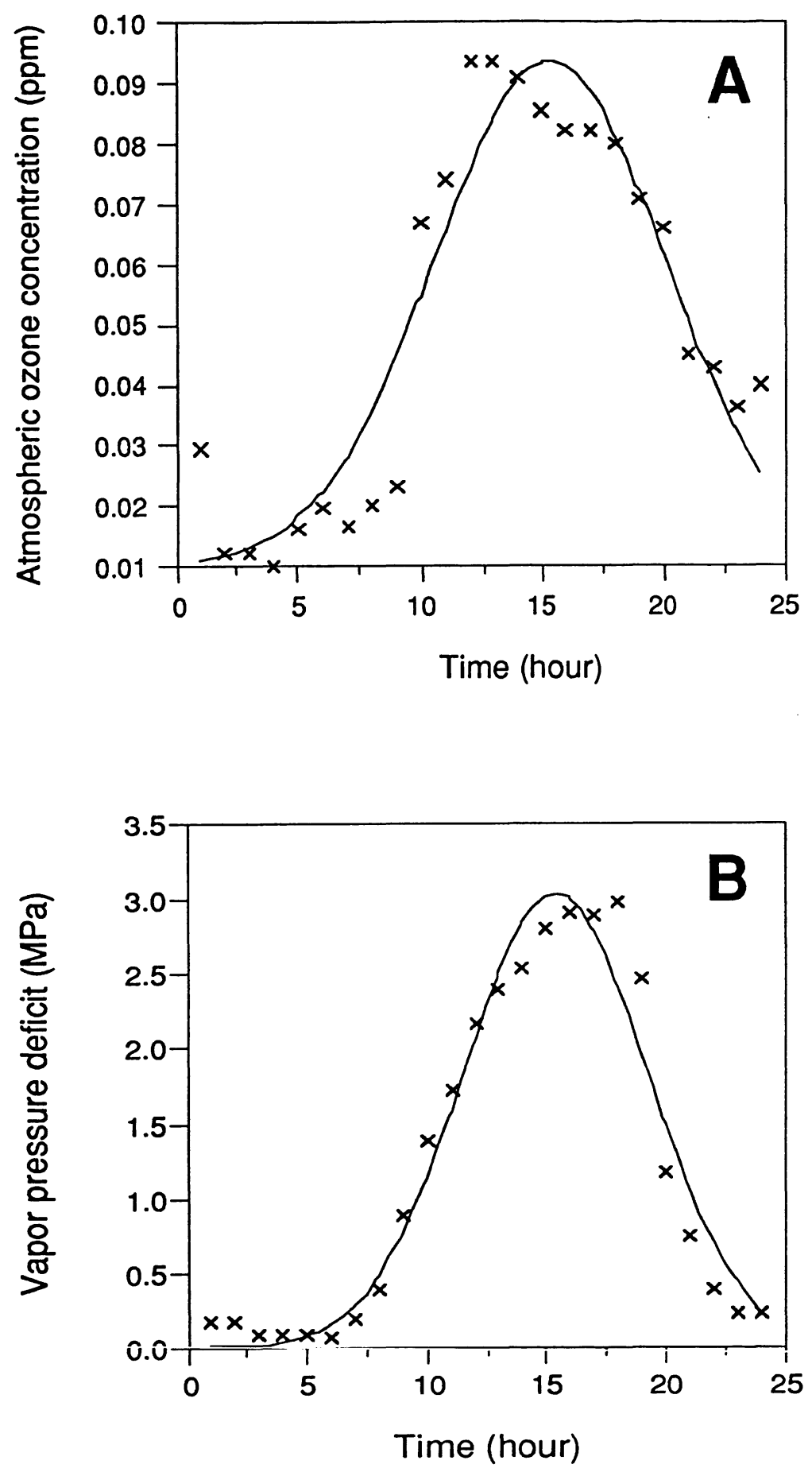

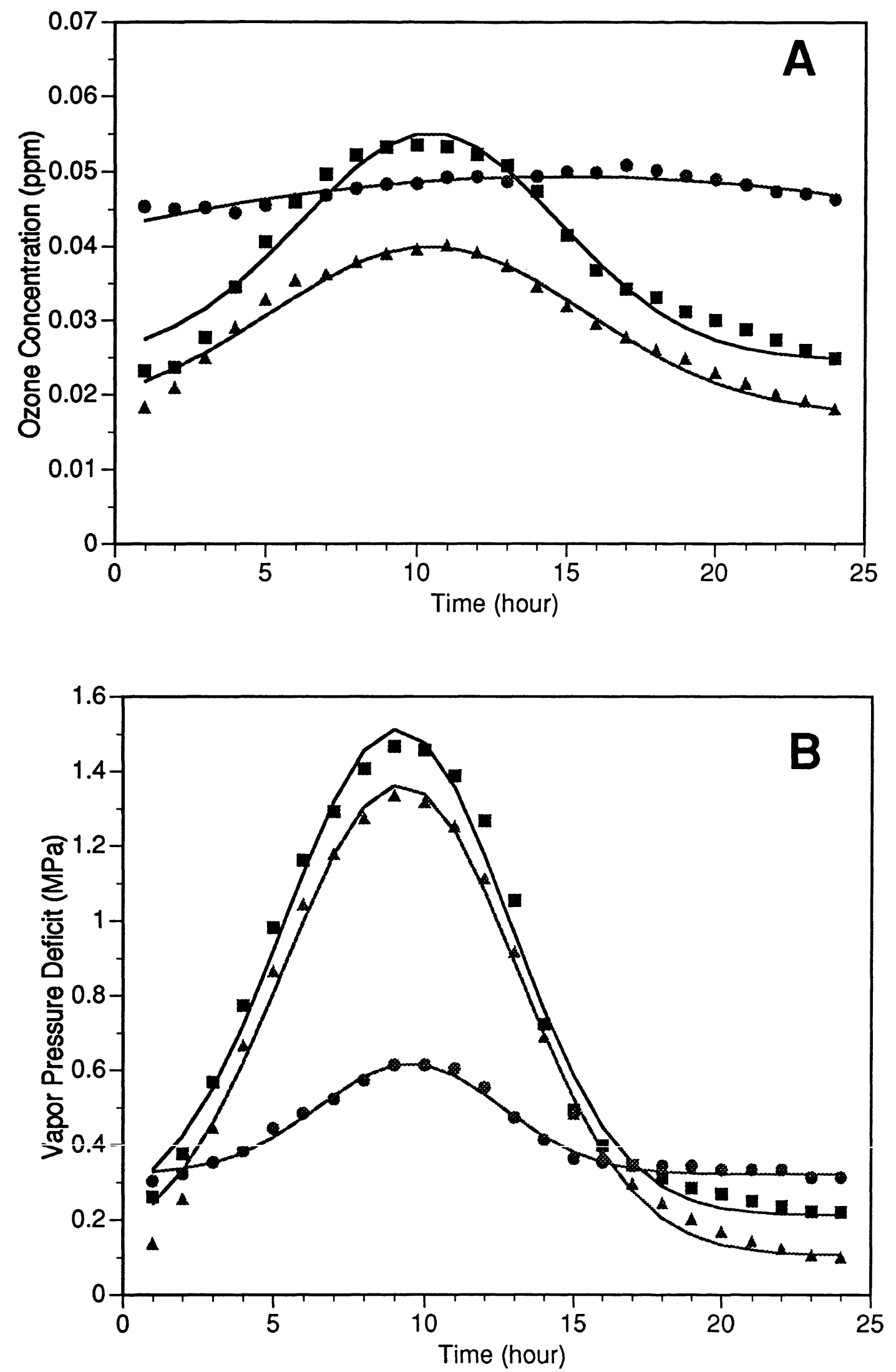


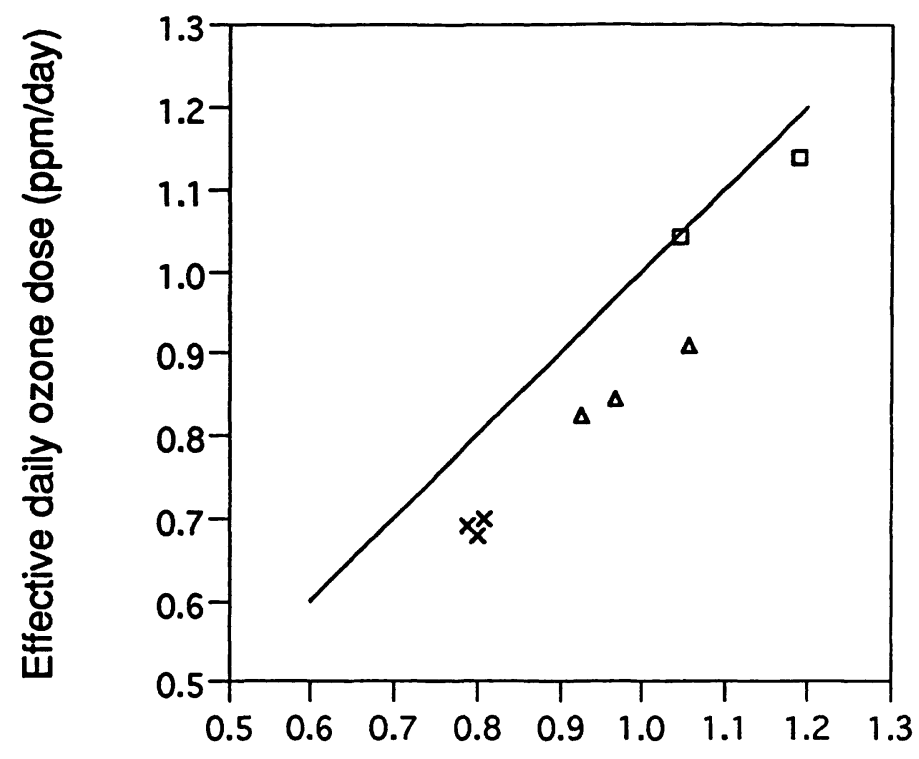

Atmospheric ozone concentration (ppm/day) 


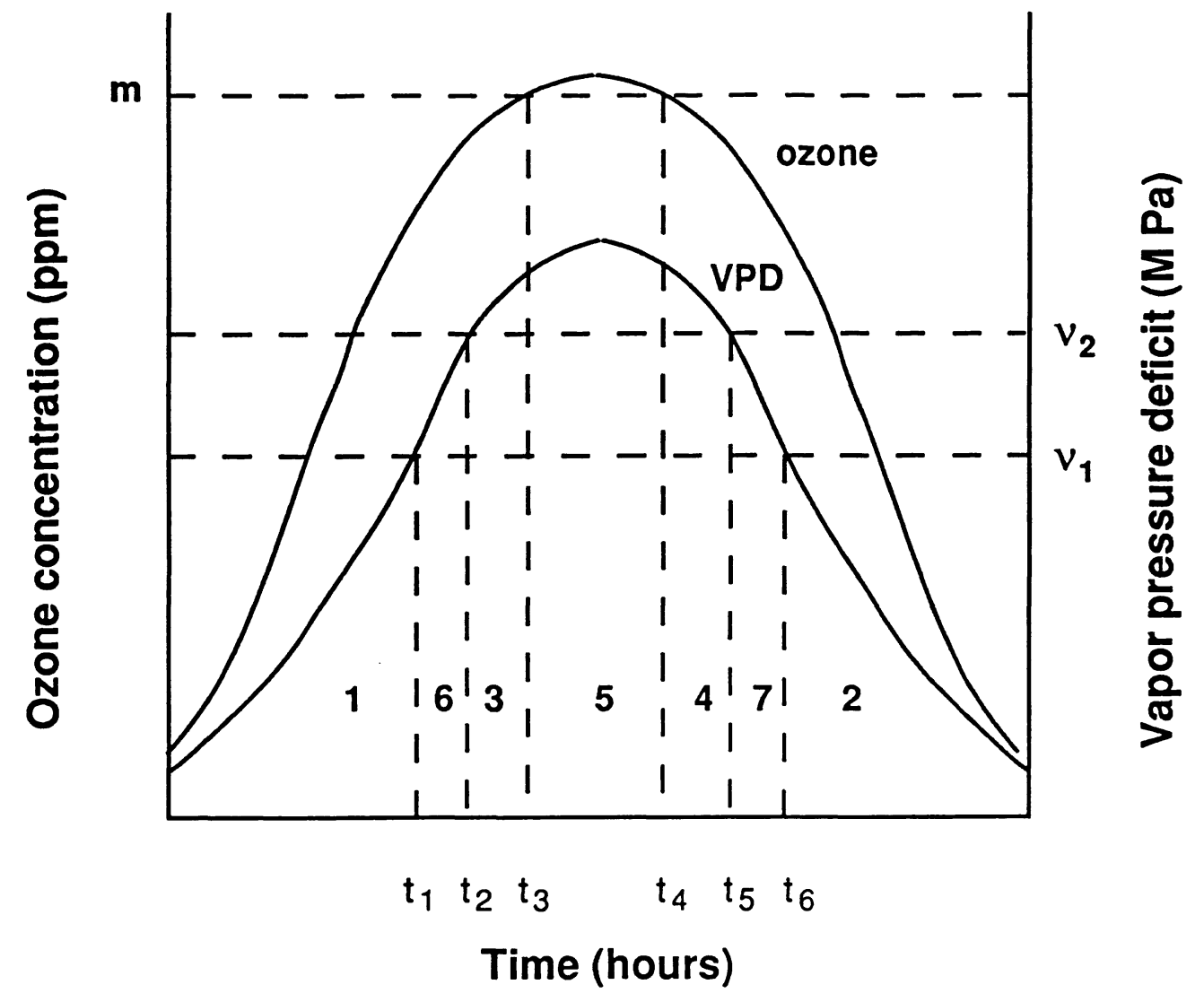

